Portland State University

PDXScholar

$7-28-2020$

\title{
"Not 'Just' a Barista": the Story of Portland's College- Educated Baristas
}

Ned William Tilbrook

Portland State University

Follow this and additional works at: https://pdxscholar.library.pdx.edu/open_access_etds

Part of the Sociology Commons

Let us know how access to this document benefits you.

\section{Recommended Citation}

Tilbrook, Ned William, "'Not 'Just' a Barista": the Story of Portland's College-Educated Baristas" (2020). Dissertations and Theses. Paper 5539.

https://doi.org/10.15760/etd.7413

This Thesis is brought to you for free and open access. It has been accepted for inclusion in Dissertations and Theses by an authorized administrator of PDXScholar. Please contact us if we can make this document more accessible: pdxscholar@pdx.edu. 
"Not 'Just' a Barista": The Story of Portland's College-Educated Baristas

by

Ned William Tilbrook

A thesis submitted in partial fulfillment of the requirements for the degree of

Master of Science

in Sociology

Thesis Committee:

Maura Kelly, Chair

Dara Shifrer

Lindsey Wilkinson

Portland State University

2020 


\begin{abstract}
This paper examines graduate jobs/skills mismatch in craft occupations, through semistructured interviews with college-educated baristas working in local and craft coffee shops in Portland, Oregon. This paper asks why college educated people work in such a role as it represents an interesting example of job/skills mismatch. Findings suggest that some see it as a good stop-gap on the way to something else, while others hope to use the skills they learned in studying for their degree to forge a career in the coffee industry. A desire to use these degree-relevant skills is prevalent throughout the sample, however many are still working out how to find a job that allows them to do so. This research adds to the existing literature by examining 'craft' jobs as inhabited specifically by college graduates who are overqualified for such positions.
\end{abstract}




\section{Acknowledgements}

I would like to thank my committee of Maura Kelly, Dara Shifrer and Lindsey Wilkinson for their help and support throughout this process, particularly my chair, Maura.

I am also thankful to all the other people who have provided their thoughts and suggestions throughout this process. In no particular order, they are: Danny Mackin Freeman, Tian Wu, Phill Willis, Sarah Florig, Jaime Wood, Tristen Kade, Luis Nunez, Essma Nasher, Jenna Depasquale, Kate Burrows, and Sara Wozniak

I am, of course, hugely indebted to all the people who gave up their free time to allow me to ask them about their job.

Finally, I would like to especially thank Sara Wozniak for looking after me through all this. 
Table of Contents

Abstract

List of Tables $\quad$ iv

$\begin{array}{ll}\text { Introduction } & 1\end{array}$

Literature Review 3

$\begin{array}{ll}\text { Methods } & 10\end{array}$

$\begin{array}{ll}\text { Findings } & 15\end{array}$

$\begin{array}{lr}\text { Discussion } & 29\end{array}$

$\begin{array}{ll}\text { References } & 32\end{array}$

Appendix A: Demographic Sheet 38

Appendix B: Interview Guide 39 
List of Tables

Table 1: Demographics of Sample 


\section{Introduction}

As US higher education institutions have admitted increasing numbers of students in recent years, increasing amounts of graduates have entered the labor market with the credential of a college degree (Clark, Joubert, and Maurel 2014). While possessing a highly-educated labor force may be viewed as a positive for a society, there is the issue of the underemployment of these graduates in jobs that do not require college degrees (and the associated debt). When these graduates cannot find a job suitable for a college graduate this type of underemployment is called jobs/skills mismatch and it is common experience among US graduates (Cunningham 2016a; Vedder, Denhart, and Robe 2013).

The larger numbers of graduates are not the only change in the labor market: an increasing amount of previously undesirable occupations now generate sought-after 'cool' craft jobs in the new craft economy such as craft distillers, brewers, and bartenders (Ocejo 2017), especially in cities such as Portland in which 'craft' industries such as brewing and coffee are prevalent (Heying 2010). Baristas are a part of the craft economy that has been relatively understudied to date. Though these craft jobs do not necessarily offer the compensation or security of those that require a college degree for entry, they may still offer fulfillment for those who are interested in the product they work with and invest in the emotional labor of the work (Erickson 2004; Ocejo 2017). Furthermore, the opportunity to play a central role in the community of enthusiasts around the product in one's craft job, and to learn about the product, may be an attraction (Ocejo 2017). Indeed, since jobs/skills mismatch can be understood as a subjective condition (Khan and Morrow 1991) it might be that for graduates who are part of the taste community, 
working in such a craft job would not subjectively be felt as jobs/skills mismatch even if a degree is not required for these jobs.

This paper investigates the educational and labor market experiences of Portland's college educated baristas. In doing so, this paper sheds light on how those find themselves in service-sector work despite being overqualified interpret their position and what their ambitions are. Specifically, this paper uses 19 semi-structured interviews with college-educated baristas in Portland. These workers are of sociological interest as they represent something of a contradiction: the career of a college graduate is not usually expected to be spent doing entry-level service work and experiencing jobs/skills mismatch. But given insights from previous research on craft jobs, there may be more to these positions than meets the eye. In conducting these interviews I answer the research question: why do college-educated people work as baristas in Portland, Oregon? 


\section{Literature Review}

Higher Education and the Graduate Labor Market

The United States higher education system has expanded to the point where over two thirds of recent high school graduates aged 16-24 are enrolled in a higher education institution (Bureau of Labor Statistics 2019). Expectations of attendance at a four-year institution is increasingly the norm among American youth (Goyette 2008; Langenkamp and Shifrer 2018; Rosenbaum and Miller 1996). However, occupational plans do not necessarily follow on from educational plans, with some students following passions (Goyette 2008; Yee 2012) or lacking a clear idea of their ambitions or how to achieve occupational plans (Langenkamp and Shifrer 2018; Reynolds et al. 2006; Schneider and Stevenson 1999; Stephens et al. 2015; Yee 2012, 2016).

Furthermore, with a higher proportion of people now holding college degrees, these degrees are now worth less in the labor market than when fewer people had degrees. This is a process known as credential inflation, where an increasing abundance of a credential makes it less valuable in securing a job as the credential requirements for jobs are raised (Chen 2015; Collins, Cottom, and Stevens 2019; Livingstone 1998). This process then means that a worker may have to earn additional markers, such as internships and extra-curricular experience, in order to gain desirable employment (Bathmaker, Ingram, and Waller 2013; Lehmann 2012; Leonard, Halford, and Bruce 2016). Due to credential inflation, college graduates may struggle to find good, secure employment in positions that require a degree for entry. With credential inflation, contacts, networking opportunities, or additional experience gained through unpaid internships become increasingly important as well as the relative prestige and reputation 
of institutions attended and programs studied (Bathmaker et al. 2013; Frenette 2013; Gershon 2017; Karen 2002; Lane 2011; Rivera 2016). A failure to get good employment coupled with the polarization of employment (Kalleberg 2011; Tüzemen and Willis 2013) puts graduates at risk of ending up in 'bad jobs'. These 'bad jobs' refer to those that pay a low wage, lack benefits, offer little chance for training and promotion and lack security and stability (Ehrenreich 2011; Kalleberg 2011; Klein 2000; Standing 2016).

\section{Jobs/Skills Mismatch}

When a person is unable to obtain a position that is suitable for their level of qualification, this form of underemployment is known as jobs skills mismatch (Cunningham 2016a; McGuinness, Pouliakas, and Redmond 2018). An example of such jobs/skills mismatch is that experienced by college graduates who take a job that does not require a college degree for entry. Approximately a third college graduates experience such underemployment in the US and often for extended periods (Clark et al. 2014; Cunningham 2016a; Federal Reserve Bank of New York 2020; Vedder et al. 2013). Such underemployment can have severe consequences. Research shows that jobs/skills mismatch can cause lower earnings in the present and future and that jobs/skills mismatch can be difficult to escape (Clark et al. 2014; Cunningham 2016b; Fogg and Harrington 2011; Ham, Mulder, and Hooimeijer 2016). There are different ways to measure jobs/skills mismatch: by looking objectively for discrepancies between the worker's skills and the job's requirements, or subjectively examining if the worker feels their skills are underutilized (Cunningham 2016b; Khan and Morrow 1991; Scurry and Blenkinsopp 2011). Khan and Morrow (1991) find that subjectively measuring underemployment predicts unhappiness with a job, whereas objective measures do not. In 
other words, workers only look upon being underemployed negatively if they perceive themselves to be underemployed - so a college graduate who works in a job that does not require a degree for entry would, by a subjective measure, not be underemployed if they felt it was a good use of their skills. Although some jobs, such as in the food and beverage service sector, may not require a degree for entry, they do require certain specific skills such as the spatial organization and memory abilities of waiting and can offer job satisfaction, for example, through the building up of social bonds with regular customers (Ehrenreich 2011; Erickson 2004; Rose 2005). Some of these jobs, such as those in the craft sector may also act as markers of taste or 'cool' and membership of a ‘taste community' (Besen-Cassino 2014; Bourdieu 1984; Misra and Walters 2016; Ocejo 2017).

Jobs/skills mismatch, therefore, has both a structural and individual component: it is a structural consequence of credential inflation, but it also encompasses individual feelings about job fit. Importantly, these two aspects of jobs/skills mismatch can operate independently of each other: one could be a college-graduate unable to earn a living wage in a job that nonetheless requires a college degree for entry, or one could be a college graduate able to earn a good wage in a job that the graduate considers to be beneath someone of their educational status and therefore experience subjective jobs/skills mismatch. Furthermore, a lack of individual perception of jobs/skills mismatch may overcome the negatives associated with its structural aspect, such as lower pay or status. 
Craft jobs

Some occupations that would typically be viewed as undesirable for a college graduate have developed 'craft' jobs. Examples of these craft jobs are working in 'cool', barber shops, cocktail bars, distilleries, and whole-animal butcher's shops as studied by Ocejo $(2010,2012,2017)$. These jobs are desirable partly because they are 'cool': indeed young people attending high school and college are known to work in particular places primarily because they are 'cool' (Besen-Cassino 2014; Misra and Walters 2016). These jobs hold a unique position: they are neither 'bad' (as they are desirable) nor necessarily 'good' (as they often lack good pay, benefits, and opportunities), but the fact that the values of the craft workplace, such as the ethical sourcing of coffee, are shared by the workers helps overcomes their 'bad' qualities to those drawn to them (Ocejo 2017). Workers are drawn to these craft jobs because they have developed an interest in the product or service and are part of a 'taste community', that is a community who are interested in the product and have ideas about the 'correct' way something should be experienced. These taste communities use this distinction in their philosophy on the product (e.g. the belief that coffee should be equitably sourced) to draw symbolic boundaries between themselves and other consumers, thereby marking themselves as 'elite' consumers and such jobs as the 'elite' strata of their occupations (Bourdieu 1984; Lamont 2000; Ocejo 2017). In this way, such jobs may offer a source of self-esteem as workers lead their professions and taste communities as experts.

As the experts of their community such workers enact the cultural repertoires that inform and educate community members about the product and guide the developing tastes of new members (Borer 2015; Ocejo 2012, 2017). Cultural repertoires are sets of 
ideas, customs and actions that help people navigate their lives (Lamont 2000; Van Hook and Bean 2009); in terms of taste communities built around them, these cultural repertoires can be understood as the technical skills, knowledge, and practices that affirm and display the values of the taste community (such as what a product 'should' taste like or how it 'should' be prepared). Though such workers may form the 'elite' of their profession and such positions do require extensive knowledge of the cultural repertoire, such jobs might not require formal training and their prestige within the taste community is not necessarily reflected outside of it (Ocejo 2017).

Barista, an Italian term literally meaning 'bartender', entered use in English in the 1980s and 90s to refer to those making and serving coffee in coffee shops. Since that time craft coffee has created a subculture (Manzo 2010): one that may be termed a 'taste community'. With such an emphasis on quality, some see the job of barista is now seen as one that requires a good deal of skill (Doorn et al. 2015; Schwalbe 2010). Skills required for the job include technical ones, both in terms of making coffee and making it look visually appealing, for example through latte art, enhancing the level of skill the customer perceives in the creation of the product (Fine 1992). Furthermore, the act of crafting a high quality product with one's own hands can be rewarding (Ocejo 2017; Schwalbe 2010; Sennett 2009). The job also involves social skills: interacting with customers, imparting knowledge about the product, and creating an inviting community meeting place away from work or home (Manzo 2015; Oldenburg 1999). Though the act of creating this inviting space requires emotional labor on the part of the barista, something that can be burdensome (Gabriel et al. 2015; Goffman 1973; Hochschild 
2012), if baristas 'invest' emotionally in their customers this emotional labor may become a rewarding aspect of the work (Erickson 2004).

Though Ocejo (2017) does not study baristas, he mentions barista as another profession where there is potentially a number of craft jobs that may attract young, educated people. Do college-educated workers who hold them feel that their elite servicesector jobs represent a good match? Indeed, these jobs represent an elite strata within baristas, they may offer high status within the coffee taste community (Ocejo 2017).

Baristas in Portland, OR

Portland, Oregon, is a city with a unique emphasis on artisan or craft products in its economy and culture (Heying 2010). This emphasis means a high concentration of craft jobs. One product that Portland is particularly known for is its coffee, hosting a great deal of trade events, education, and barista training in the city, as well as a high concentration of craft (or 'third wave') shops (Hutchens 2013; Ragain 2010). In a city that prizes good coffee and high-quality artisanal products, some baristas earn good money and receive benefits form their jobs (Ragain 2010). Perhaps this is unsurprising as baristas are charged with the running of favorite community hangouts in the city and therefore play an important role in the social life of the city. By the fact that there is a taste community around coffee, and that Portland is known to host a high concentration of coffee shops, it seems likely that if there are desirable craft barista jobs, they will exist in Portland. Furthermore, with the value placed on coffee by Portlanders, it may be work that such is held in high esteem by customers as these baristas would be central to the taste community. 
Working as a barista also presents challenges. Such work can be "bad jobs," insecure and poorly paid, indeed baristas across the US have recently begun drawing attention to their compensation through wage transparency. In September 2019 an anonymous Philadelphia barista shared pay information via a google survey and soon baristas in multiple cities began sharing their pay to draw attention to the issue of low pay in the industry (Batory 2019; Sedacca 2019), with barista union drives occurring due to such issues in Canada (Brickner and Dalton 2019). Ninety-two Portland Baristas had contributed to the Barista Wage Survey at the time of writing. Clearly, baristas do face challenges in their job around security and pay that suggest such a job could mean a college graduate is in a position of jobs/skills mismatch. However, by the subjective measure of jobs/skills mismatch a graduate would only be in such a position if they did not feel their job was suitable. Those college graduates who invest in and enjoy the emotional labor aspect of the job as well having an interest in coffee may find barista work satisfying. Graduates working as baristas, especially in craft coffee shops, offer something of a puzzle. Do they see their work as desirable, or are they there because they cannot access, or have given up on trying to access, good jobs suitable for their level of qualification? Furthermore, the city of Portland, Oregon offers a perfect place to find the answer to this question. With its focus on artisanal products in general and coffee in particular, this represents a perfect setting to investigate the careers of college-educated baristas. 
Methods

In this study, I conducted qualitative interviews with a total of 19 baristas between September 2019 and March 2020. In order to participate in the interview study, a barista had to hold a college degree (most participants have four year degrees, although one has an associate's degree and two certificates within the same discipline), not be currently in further education (as currently studying would likely indicate a temporary stop while earning a further qualification), and work in a coffee shop within the Portland Metropolitan Area (one participant who had barista experience was looking for a barista job in Portland while working another coffee job). In this study, Portland represents a unique site with a myriad of independent and locally-owned coffee shops (I visited 121 such shops during participant recruitment) that often focus on the high quality of their product. Therefore, in order to focus on these jobs, I excluded baristas who worked at large national chains such as Starbuck's or Peet's. In defining coffee shop, any shop first had to have an espresso machine to be included in my definition. I included places that served some food but excluded sit-down restaurants with full table service. I further excluded drive-thru coffee stands, focusing on shops that allow for on-site consumption. I recruited by speaking to the baristas working and leaving flyers on site. In doing this I started in downtown Portland and gradually fanned out to surrounding neighborhoods, eventually reaching the suburbs. I also posted on a Portland Baristas Facebook group in order to recruit. The sample is a convenience sample, with some additional participants recruited using a snowball sampling.

Interviews took place in coffee shops and restaurants, wherever the participant felt comfortable. For many baristas, the most convenient time for them to meet was 
immediately prior to or after a shift, so some interviews did take place in the participant's own place of work. However, as the interview guide contained a question concerning what they did not like about their job, in these instances I endeavored to secure a place for us to conduct the interview outside or otherwise out of earshot of supervisors. Interviews generally lasted 30-40 minutes, with the shortest one lasting 14 minutes and the longest lasting 66 minutes.

Questions were semi-structured and open ended, with prompts included in the interview guide in order to ensure certain data is collected from every participant. Both the demographic sheet and interview guide are available in the appendices. On the demographic sheet, I collected data on gender identity, race, number of years since graduation, college attended, and where participants are from. Interview questions focused on participants' reasons for going to college, how they came into their current position, their opinions on their current job, and their ambitions and goals for the future. Interviews were recorded and then transcribed. Pseudonyms have been used for all participants, as well as for the coffee shops at which they worked.

Full demographic details for the 19 participants are contained in table 1, with the sample skewing white and female. While race and gender are not the foci of this study, some experiences that are shaped by race and gender could have been missed. Most participants were younger graduates who were traditional students and had completed their degree since 2012. These participants, therefore, were aged between their early $20 \mathrm{~s}$ and early 30s. Three participants completed their degrees earlier in 2000, 2006 and 2008 respectively. Though some participants were shift leads and shop managers, they all 
worked mostly behind the bar. One participant owned the shop where she worked, however her and the co-owner were the only two people to work there at the time of the interview.

\section{Table 1: Demographics of Sample}

Total

Gender

Female

Male

Non-binary

Race

White

Asian

Mixed race

Position

Barista

Shift lead/supervisor

Location/store manager

Owner

Coffee tour guide

$\begin{array}{rlr}19 & \text { Year graduated } \\ & 2000 & 1 \\ 13 & 2006 & 1 \\ 3 & 2008 & 1 \\ 3 & 2012 & 2 \\ & 2013 & 3 \\ 16 & 2015 & 1 \\ 2 & 2016 & 1 \\ 1 & 2017 & 3 \\ & 2018 & 3 \\ 13 & 2019 & 3 \\ & \text { Major (Double majors may be counted } \\ 2 & \text { twice) } \\ 2 & \text { Business } \\ 1 & \text { Linguistics \& languages } & 1 \\ & \text { Social sciences \& } & 3 \\ 1 & \text { humanities } & 7 \\ & \text { Performing arts } & 2 \\ & \text { English \& journalism } & 3 \\ & \text { STEM } & 2\end{array}$

Considering my positionality (as a white man and a graduate student), I feel it had some bearing on this project. Though the sample skews female and non-binary, none of the interview questions concern these identities directly. Of course, interviewees who did not share my positionality may not have shared certain data with me, such as the women 
in this heavily female sample not feeling comfortable disclosing information about sexual harassment to a male interviewer. Though I did collect some data on this particular matter, I am unaware of how much I missed due to my positionality. Another potential problem with positionality was my role as a graduate student. As I interviewed people who have left education are over-qualified for their jobs is a possibility that they felt some regret at not using their degree in their employment. However, although graduate studies are seen as a pathway to high-status positions, being a graduate student in itself is more often associated with poverty than riches and has a much lower status than the jobs it leads to. Furthermore, while I have never been a barista, I have been underemployed since I graduated from my undergraduate degree myself. Where appropriate, I shared some aspects of such experiences, and other relevant information about myself, in order to build rapport with participants.

In analyzing the data, I used an abductive approach: this is where the researcher enters the coding and analysis process with some ideas of what they might expect to find from knowledge of prior research, but still allow new and unexpected themes to emerge when present in the data (Korver-Glenn 2018; Timmermans and Tavory 2012). This mode of data analysis begins with looking for patterns in the data and data analysis and collection is reflexive process where the researcher moves between the two tasks (Marvasti 2003). This approach suits the research question as it is open ended and seeks to broadly understand how the participants interpret their reality. I used the qualitative data analysis software Dedoose for this process. 
In the coding, two broad types of answers to the research question emerged. The first of these concerned the day-to-day aspects of the job, as well as the pay and benefits, especially as compared to other available jobs. These answers are addressed in the first half of the findings 'on the job' in which the satisfactions of tactile work and interacting with customers, being part of a taste community, and compensation are each discussed in turn. The other type of answer were those that emerged from baristas' discussions of their education, how they became a barista, and their future plans. These are discussed in the second half of the findings 'becoming \& remaining a barista.' This section starts with a discussion of what attracted participants to higher education and to their major before identifying a typology of baristas by their ambitions: those who see their job as temporary and low-stakes (passers-through) and those who see a barista job as the first step in a career (careerists). 
Findings

On the Job

Making \& Socializing

Baristas I interviewed frequently mentioned that they enjoyed working with their hands to create a high-quality item from a product they were enthusiastic about. As Hannah says: "I get to make one thing at a time ... put detail and effort into that and give it to someone, that's just really fulfilling and simple and lovely." This satisfaction in making high-quality items is not something unique to baristas and has been found in other craft jobs (Ocejo 2017; Schwalbe 2010; Sennett 2009). For some, given their education and other work, this more manual experience was novel: "After doing a lot of cerebral work as a writer, it's really cool to have a more tactile experience, you feel the hot pitcher... you smell what's going on around you" (Harper). Others have disavowed less active work, having decided that such office work is uninteresting to them "I was bored ... inside at a desk staring at a computer. I just didn't like the lifestyle." (Chloe). Craft jobs are known to attract educated workers disillusioned with white-collar jobs, this suggests that for these workers such jobs are not a mismatch (Khan and Morrow 1991; Ocejo 2017).

Another part of the day-to-day work of barista that participants enjoyed was the opportunity to have a small, positive impact on a person's day every day and to build up relationships with regulars. Evelyn told me that at one job they "saw [regulars] get married and have babies ... getting to know the regulars, what they want and watching them and being just this little point in their day every day and checking in ... it's really fulfilling for me." Lily also saw considerable value in the small interactions she would 
have with customers every day and the impact they could have: "I have the opportunity to show someone that I see them and their value just in our small interaction." These are examples of baristas choosing to invest in their emotional labor, gaining satisfaction from exchanges with customers and forming relationships with them. This strategy of investment in emotional labor is used by waiting staff to gain more enjoyment from their job (Erickson 2004). However not all baristas chose to engage, and some emphasized the more negative, emotionally draining aspects of emotional labor (Erickson 2004; Hochschild 2012), such as Liam who told me that it is 'not satisfying' being 'a servant'. Even those who enjoyed this part of the job, such as Evelyn, did acknowledge that it could be 'exhausting' and that rude customers could interrupt their enjoyment of this part of the job. Such experiences suggest that those baristas who do not enjoy the job do feel that the job is a mismatch.

\section{Coffee in Portland, OR}

Although some participants were not particularly enthusiastic about their occupation as a barista, there was a sense that Portland was a good place to be one. Baristas mentioned the opportunity to taste and learn about different coffees, attend 'throwdowns' where baristas show off their latte art skills, or even go on employersubsidized origin trips (where they are shown the farms that grow the coffee sold in their shops) as part of their professional development. Such opportunities are perhaps unsurprising since, as Isobel points out, coffee is important in Portland:

I would compare it to the way people in the north talk about soup ... they talk about it with this reverence like it's this really important thing. People in the south don't talk 
about soup that way. There's just kind of like a seriousness about coffee that I haven't encountered as much in other places.

For some career-oriented baristas, the coffee scene and the ease with which they could pick up a job and learn about coffee was a reason for moving to the city, indicating the weight of the reputation of Portland's coffee scene (Hutchens 2013; Ragain 2010). The wealth of experience, knowledge, and skill available in the Portland coffee scene make it an attractive place for those who are interested in developing their trade. The specialized skills and knowledge that baristas possess represents the 'cultural repertoire' of the coffee community in Portland. The cultural repertoire, in the context of the coffee community, are actions and ideas that represent the values of the community and how they feel coffee 'should' be sourced, prepared, and consumed (Ocejo 2017). Baristas are at the vanguard of the coffee community with their knowledge of the product and how to prepare it. They use these cultural repertoires to educate customers and enhance their enjoyment of coffee, as well as to interest new people in coffee. In this way baristas act as cultural intermediaries between production and consumption, increasing the value of the product and educating customers in coffee culture through their labor (Ocejo 2012). For example, Aurora described how she would mentally log the types of coffee a customer enjoyed to help make recommendations and enhance their enjoyment of coffee:

I'll be like, 'cool, you enjoy natural processes' ... I remember that for next time. So that conversation of just starting to build what people like and not them just having to show up and be like, I just want a coffee I'm like, 'well, I have a single origin on our drip that you'll probably like it's got chocolaty notes; here's a sample' and they'll be like, 'wow, this is really good.'

A particularly important part of the cultural repertoire for many baristas was the provenance and sourcing of their product. Baristas recognized that information about 
where their coffee had come from and how it was sourced was important (Jaffee 2014). Those who believed their shop was sourcing its products ethically took pride in this and their ability to relay such information to the customer was important. Grayson placed emphasis on his employer having oversight of the entire process: "we do make sure that the right people are being paid because so often people will purchase a coffee and ... the wrong person will get paid for the product ... If you get to know your supply chain ... your ethical transparency of product is there."

Customers who are part of this taste community are valued by baristas as they recognize the skill of baristas and are interested in the work that they do. Hannah says of the customers at her job "people are always really excited to try our drinks and they come back often." However, such good customers are not always common. Aurora pointed out that "I don't get to flex myself all that often when it comes to my knowledge, my experience. I would say maybe one in every ten people." On the other hand, some people outright failed to see much worth in their work as baristas. These are those who see barista as just another low-wage service sector job that requires no great skill. Lily sums up this stereotype when she says: 'talking to people about my job, they're like, 'Oh, she's just a barista.' And to me, that's kind of [pause] I don't feel like that says ... the whole picture because I don't feel like I'm 'just' a barista." These customers see barista as a 'bad' job (Kalleberg 2011), and fail to recognize that even if it is a 'bad' job such work still requires specialized skills and knowledge, especially among those working in the craft sector (Ehrenreich 2011; Ocejo 2017; Rose 2005). 
In addition to these negative stereotypes, women in particular can face additional difficulties in the industry. Female participants mentioned how craft coffee was dominated by men in management positions, to the point where Ella, a white woman, after an interview at a Portland coffee shop, questioned if she wanted to work somewhere so heavily white and male dominated: "[the interview panel] was three men and they were all training managers, cafe managers, their owner's a white man, their other cafe manager was a white man and it just got me thinking about my potential ability to thrive in a place like that." Ella turned down an offer from that shop in favor of another. Abigail said she 'harassed out' of her last job, but expressed that such things were normal, saying "when you start working in service when you're 16, [it] becomes really apparent that [sexual harassment] is what's going to be happening."

\section{Compensation}

When participants discussed their wages, what they made generally ranged from minimum (at the time of the interviews, $\$ 12.50$ in the Portland Metro area) to $\$ 15$. When asked about tips, the majority of baristas answered that they made between $\$ 5$ and $\$ 6$ an hour, though some made considerably less. Altogether this meant that most of the participants made approximately $\$ 17-\$ 21$ an hour. Twelve participants worked between 30 and 40 hours a week and seven baristas worked fewer. Some participants had other paid work, though these were mostly ad-hoc. Though these wages hardly represent riches in the Portland area, participants generally felt it was enough to get by on. In fact, some who had held white-collar professional positions or who had considered them noted that with the tips they were actually able to make more money: "I make more as a barista than 
a social worker, which is quite sad." (Evelyn.) For some college-educated baristas their current job represents a financial step-up from entry level jobs in the field their degree is in. This suggests that financially at least, baristas jobs often do not represent any more of a mismatch than entry-level white-collar jobs.

Although tips represent an important part of participant's income, these were not always reliable and some expressed frustration that the expectations around tipping in coffee were not as clear or generous as in other service industry occupations. Aurora compared baristas to bartenders in this regard:

On a Rainier [beer], [bartenders] get a dollar [tip], flat ... \$2 if you're doing good cocktails. Whereas I'll walk someone through single origin coffees all day long to try and get them to buy a bag, and I don't see a dime ... or I'll go I know that you typically get your americanos, but I'm going to do it with the same origin that we're pulling today ... go through the rigmarole and get nothing.

The issue of this less-than-ideal compensation is then compounded by its inconsistency: tipping can be better or worse depending on the time of day and year, and hours can be inconsistent in both the amount and the scheduling. Some participants even mentioned managers who would cut down on the hours of employees they did not like. Isobel told me that "we get different hours every week, and we don't find out what our hours are going to be for the week until the weekend." This issue was particularly difficult for Isobel as she had a young child to look after. This lack of stability represents a feature of 'bad' jobs, with the lack of consistency in hours or income in particular acting as a source of instability and insecurity for baristas (Ehrenreich 2011; Kalleberg 2011; Standing 2016). Though many of the baristas in this sample enjoyed their work and wanted to stay in the coffee industry this lack of stability and less-than-ideal pay meant 
that the role of barista was not seen as a viable long-term option even by those who enjoyed the job.

Turning to benefits, some had healthcare, paid time off, and even retirement benefits through their work. However, having access to these was far from the norm. Evelyn asserts that part of the reason that baristas are typically not offered such benefits is due to a perception of the job as undeserving of them:

It's accepted within the industry that of course we don't have benefits, of course we don't have paid time off, of course we don't have insurance, of course we can't afford that and it's written off ... as the system's fucked and [pause] I think it makes it totally unsustainable for all of us to be in this as long, even if we're very happy in every other way.

Here, Evelyn suggests that if such benefits were offered they might be more interested in continuing to work as a barista long-term. Furthermore, they suggest that part of the reason they are not offered benefits is because of some stereotype of barista as a low-skill 'bad' job that is not deserving of such benefits (Ehrenreich 2011; Kalleberg 2011; Klein 2000). Indeed, a lack of healthcare was given as a reason to not want to stay behind the bar. When discussing why he wanted to leave the industry Liam said "I have really bad back issues ... I can work 40 hours a week and hurt my back and I could lose my job and there's no security and there's no health benefits, nothing." For many of these baristas money or a 'career' befitting a college graduate was not their primary concern employment-wise, with Evelyn saying they enjoyed a "simple life, I don't care if I ever own a house, I like having few possessions." However, as noted in Evelyn's previous quote above, these people still need some greater amount of security and stability to keep them in the job long-term. 


\section{Becoming \& Remaining a Barista}

Having examined the aspects of their work in which college-educated baristas find enjoyment (or a lack thereof), I now turn to the ways in which these degree-holders became baristas and what they plan to do in the future. For some, they were never sure what they wanted from their degree in the first place. Having worked as a barista during their education, they simply continued while they decided what to do next. Others are unable to find something in their field or are taking a break from another career, falling back on a familiar occupation. For some such people they already had an interest in coffee and saw baristas as a 'cool' job when they were in high school, with Aurora remembering "I always thought being in coffee was really cool, which sounds dorky, but I was all like, 'whoa, [that barista's] got jade gauges and piercings, that's really tight."'

Participants mentioned that they felt they needed to have a degree, even if they weren't quite sure what they wanted a degree in or the job they wanted afterwards. For example, when asked why she felt she 'needed' a degree Harper said "I was working in a customer service call center and I knew that if I didn't have some kind of degree that I was always going to be working in a customer service call center. I don't know that that's really true. But that was what I told myself.” Here Harper acknowledges that this urgency may not have been necessary. This pressure to have a degree is a consequence of attending a four-year college becoming the norm amongst American youth (Goyette 2008; Langenkamp and Shifrer 2018; Rosenbaum and Miller 1996). Evelyn had also felt the pressure of such expectations: "[I] just kind of did what all my teachers [said], which ... for every student was college, college, college.” Like Harper, Evelyn acknowledged 
that this urgency for education may not have been best for them, adding that they thought youth should be encouraged to take time out of education after high school.

For others employability or a career in the same field that they majored in, while desirable, was never the main reason they chose their major or to attend college. For baristas such as Hannah, following an interest was the most important factor in postsecondary decisions: "I chose English because I write and books are important to me so I was like I'm going to study the things I'm passionate about and just see what happens." Though Hannah and others expressed a desire to work within their field and had made an attempt to find employment within it, they had come to understand that this may require additional education or experience. These baristas had often lacked knowledge of how to get into a desirable position (for example being unaware for the need for additional experience besides their degree) suggesting a 'decoupling' of occupational and educational plans in which students are unaware of how to achieve their occupational ambitions (Goyette 2008; Langenkamp and Shifrer 2018; Reynolds et al. 2006; Schneider and Stevenson 1999). Among the participants, some frustration at not fully utilizing their degree was common, suggesting this decoupling of occupational and educational plans is a source of frustration for college-educated workers after graduation. Participants spoke of the debt they'd accrued for an education that had left them with a job they did not require one for; for Lily this pressure came from her mother who claimed she was 'leaving money on the table'. Experiences and frustrations such as these suggest it is difficult for college-educated baristas to get away from the perception (from others or oneself) of experiencing jobs/skills mismatch. As such it may be difficult to not see 
oneself as underemployed and therefore experience jobs/skills mismatch subjectively (Cunningham 2016b; Khan and Morrow 1991; Scurry and Blenkinsopp 2011).

Passers-through

Eleven participants were passer-through baristas: those who aim to leave their barista job and the coffee industry for another career. Often this career requires some further training or graduate studies. Passers-through may have worked a barista previously, left the industry, and then returned to the job for a temporary change. This did not necessarily mean they wanted to work in the same field they majored in, though most of these baristas did intend to use their degree in some way. Their desire to leave the industry for something else did not, however, mean that they disliked their job or looked forward to leaving: while some were eager to find something else and were frustrated in their job others looked to their eventual exit with reluctance. Amelia had a long-held ambition to own a music venue, but loved working in coffee saying she wanted to stay in the industry 'for as long as possible'. This enjoyment of her job suggests that for Amelia the 'cool' aspect of the job was able to overcome its negative aspects (Ocejo 2017). Others were continuing with a job they had held during their education while they decided on, or prepared for, their next move. Oliver was in this process:

I decided to take some time away from school, have a transition period between undergrad and grad school and right now I don't know if or when I will be going to grad school, I still want to but it's kinda up in the air ... I also wanna ... live through adult life a little bit before I launch myself back into something that might put me in more debt.

Oliver continued working as a barista and deliberately used it to form part of a transitional phase in his life. This view of jobs/skills mismatch as an undesirable, but 
temporary, position suggests that while underemployed graduates do subjectively experience jobs/skills mismatch they also do not think they will be in such a position forever (Cunningham 2016b). Furthermore, this presence of further plans suggest that while some college-educated workers come to be baristas because of a disconnect between their educational and occupational plans (Goyette 2008; Schneider and Stevenson 1999), others already know that their ambitions require additional qualifications due to the credential speedup but take breaks on their path towards these ambitions.

For passing-through baristas, working in a coffee shop was the preference among low-stakes jobs that they could pick up. For example, Liam had tried his hand at working in a bar but 'didn't like the happy hour crowd' and preferred the smell of coffee to 'rotting yeast'. For some passers-through, such as Chloe, the ease with which they could pick up and drop the job was an attraction: "It's probable that I'll end up with another barista job at some point in my life, just because ... it's like really easy to pick up and let go." For these baristas, working in a coffee shop represents a low-stakes stop-gap or backup occupation. While they may enjoy it and find it interesting, perhaps staying for a considerable amount of time, it is not intended to be a career. Ella sums this up: "As much as I've loved working in coffee, I don't think I ever saw it as a career ... it was just a hobby that I was really good at that I was interested in, that I made a lot of friends in, learned a lot, but I'm not gonna stay.” These baristas have varying degrees of strength and clarity about their future ambitions for their work and career, but what they hold in common is that they see their future outside of coffee. 


\section{Careerists}

Eight participants were careerist baristas: those who expressed a desire to stay in the coffee industry, planning to be shop managers and owners or work outside the shop as roasters or importer/exporters. Though the vast majority of participants expressed at least some positive feelings towards the job, careerists are those who can see a path to a fulfilling career in the industry. This does not mean that this was their first-choice career - generally this is an ambition that they have adopted reluctantly or after a career setback elsewhere. Though for some these ambitions really were primarily rooted in a love of coffee and coffee shops, they were also at least partially rooted in a lack of other opportunities or frustrations with another job. For example, Sidney, who has a degree in Japanese, started working as a barista after having to return home from living in Japan due to a family crisis. At first working as a barista was meant to be temporary but when I spoke to them, Sidney said:

What if ... I find a job ... with coffee, but Japanese is not relevant to that at all? Maybe I'd go that direction at this point, because even though I spent four years spending money to learn the Japanese language, if it ends up I could get a good job where I can climb the ladder and have the salaries and benefits and everything and really get a good position and a good career for myself and I don't use my degree at all, that's something I would consider. Absolutely.

Here Sidney expresses an openness to career in coffee, even if it doesn't use their degree, as long as it represents a good, stable position. However, Sidney, like others who expressed careerist ambitions, still sought a way to use the skills gleaned from their education in a coffee career. Those with foreign language skills were interested in importing and exporting coffee, while Grayson, who has a degree in Theater Arts and Performance, spoke of hiring new baristas being like 'casting a play'. Here, those who 
look at careers in coffee actively seek a way to realign their new occupational plans to their education, even if such a realignment is difficult to make happen in practice. For some participants it was unclear how they would be able to use their degree in the coffee industry, suggesting this process of realignment was, in some instances, rather forced. But this realignment, forced or not, serves a purpose as a way to combat subjective feelings of jobs/skills mismatch. Even though they experience it in the present as a barista, it allows them the knowledge that they do have a way out of it to a job that uses their degree, whether or not this ultimately occurs.

It is also important to note that these careerist baristas, while wanting to stay in the coffee industry, rarely wanted to work in the role of barista indefinitely. Concerns about injury were mentioned and plans were made to move elsewhere in the industry. Grayson, for instance, wanted to learn to work in various different roles within the industry, saying that: "diversifying my skill set will increase my longevity with this work." However, finding ways to learn those new skills and acquire new positions within the industry can be challenging. While the path to store manager and even owner are fairly well-trod and established, paths into other industry positions that take place in different physical locations were more difficult to access. Evelyn, for instance, said "I'd really like to find a way to end up on sort of the exporting or importing side of things, but I don't ever want to lose connection to the final product in the café and I have no idea what that looks like." Here, Evelyn indicates that they are interested in a long-term coffee career that is something other than working behind the bar, but finds that the responsibility lies with them to work out exactly what that career is and how they can 
access it. This lack of opportunities for advancement is a feature of 'bad' jobs (Kalleberg 2011). Another theme that some female participants mentioned was that gender discrimination meant it was harder for women to access some positions. Aurora was in the process of learning to roast through her employer, but acknowledged that accessing roasting can be especially difficult for women: "it's very difficult for women to get into production to get into roasting ... there's a lot of gate keeping with information."

This lack of established pathways can even turn away potential careerists. For example Charlotte, a passer-through barista, enjoyed her role as a shift lead at Early Rise Café, but could see no way forward except leaving coffee: "I probably wouldn't ever say I would stay at the shop forever because there is no upward motion. I've kind of reached that. I don't really want to be a shop manager cause then you don't do any of the fun parts of the job." Here Charlotte sees that management is the only really accessible way forward for a career in coffee and this is simply not a job that appeals to her, leaving her certain that the only future career for her lies outside the industry.

While careerists enjoy their work, can see themselves staying in the industry indefinitely, and are often very keen to do so, they are hampered by a lack of clarity about how to achieve these ambitions. Though some are further along the process of developing their career in the industry than others complete clarity about what they wanted from a career in coffee was scant. Many of those who were considering a careerist path were also not entirely convinced it was what they wanted or would ultimately end up pursuing, but saw it as an option. 


\section{Discussion}

College-educated workers are baristas in Portland, Oregon due to an interest in coffee and a preference over other service-industry jobs. For some baristas, that next move is away from coffee. They either realize or were always aware that their undergraduate degree is not enough to access a desirable job in their field due to the credential speedup (Chen 2015; Collins et al. 2019; Livingstone 1998) and plan to return to education or access further training to help them get another job at some point. For others, that next move is towards a different job in coffee, and their barista job can be conceptualized as playing a similar role to an entry-level white collar job in a career plan: it is the first step on the ladder. For such graduates their entry-level service positions are still temporary, but because they plan to move upwards rather than sideways.

This study contributes to the literature by understanding how graduates who work in 'cool' craft jobs view their position and reconcile it with the jobs/skills mismatch they experience. For some, this reconciliation is achieved through an understanding that this position is only temporary, while for others it is through planning for such a job to be the first step in a career that will lead them out of jobs/skills mismatch. However, these graduates still subjectively experience jobs/skills mismatch. In this study, this was because they still knew that they were underemployed, and this was reinforced by others who see them as 'just' a barista and by a lack of benefits reminiscent of temporary, lowskill jobs. However, for those who do work in craft service industry positions these negative aspects of the job can be offset partially by working with a product that they are interested in, developing their knowledge, and being a on the leading edge of their taste community, regardless of their ultimate ambitions (Ocejo 2017). In understanding how 
the craft sector works we are able to understand a mechanism through which college graduates mitigate the negative experience of jobs/skills mismatch.

In order to reduce subjective jobs/skills mismatch in such craft jobs, a couple of changes may help. Firstly, since the lack of benefits and healthcare in particular were a marker that indicated to such workers that they were in a job that should be considered temporary or not worthy of a college graduate, access to healthcare might change perceptions of the job among those who work there. Secondly, a lack of established career pathways to a variety of roles within such jobs may allow people who want to stay in their craft industry the opportunity to do so, and having clear opportunities for advancement would further distance such occupations from 'bad' jobs. Other possible changes to reduce subjective jobs/skills mismatch could come from education: one reason participants felt pressure to use their degree was due to the cost of higher education. Reducing the financial burden on students would reduce this pressure and signal that higher education is not necessarily a financial investment upon which a return must be sought in order to make such an investment worthwhile.

Future research could focus on how those who work in different positions within the craft strata of industries such as coffee access more senior and varied positions and how they could be made more accessible. Another potential direction is if better compensation and benefits for those in a position of jobs/skills mismatch relate to lesser subjective feelings of jobs/skills mismatch since a lack of benefits in particular was a mechanism through which some baristas felt their underemployment. Another area for future research to focus on is how unclear occupational and educational ambitions before 
and during college relate to jobs/skills mismatch after college. Further understanding jobs/skills mismatch in craft jobs is important as many will experience this form of underemployment due to the credential speedup, and craft jobs and careers offer people in such a position a way to mitigate the negative aspects of it and find enjoyable employment that is related to their interests. 


\section{References}

Bathmaker, Ann-Marie, Nicola Ingram, and Richard Waller. 2013. "Higher Education, Social Class and the Mobilisation of Capitals: Recognising and Playing the Game.” British Journal of Sociology of Education 34(5-6):723-43.

Batory, Craig. 2019. "Behind the Big Bang of Barista Wage Transparency." Daily Coffee News by Roast Magazine. Retrieved March 20, 2020 (https://dailycoffeenews.com/2019/10/21/behind-the-big-bang-of-barista-wagetransparency/).

Besen-Cassino, Yasemin. 2014. Consuming Work: Youth Labor in America. Temple University Press.

Borer, Michael I. 2015. "Consuming Craft." Pp. 297-305 in Popular Culture as Everyday Life, edited by D. D. Waskul and P. Vannini. Routledge.

Bourdieu, Pierre. 1984. Distinction: A Social Critique of the Judgement of Taste. Cambridge, Mass: Harvard University Press.

Brickner, Rachel K., and Meaghan Dalton. 2019. "Organizing Baristas in Halifax Cafes: Precarious Work and Gender and Class Identities in the Millennial Generation." Critical Sociology 45(4-5):485-500.

Bureau of Labor Statistics. 2014. "College Enrollment and Work Activity of 2013 High School Graduates."

Chen, Victor Tan. 2015. Cut Loose Jobless and Hopeless in an Unfair Economy. Berkeley: University of California Press.

Clark, Brian, Clément Joubert, and Arnaud Maurel. 2014. The Career Prospects of Overeducated Americans. Working Paper. 20167. National Bureau of Economic Research.

Collins, Randall, Tressie McMillan Cottom, and Mitchell L. Stevens. 2019. The Credential Society: An Historical Sociology of Education and Stratification. Columbia University Press.

Cunningham, Joseph. 2016a. "Credential Disconnection: A Marxist Analysis of College Graduate Underemployment.” Critical Studies in Education 57(2):224-37.

Cunningham, Joseph. 2016b. "Genres of Underemployment: A Dialogical Analysis of College Graduate Underemployment." Qualitative Research in Education 5(1):124. 
Doorn, George van, Maxwell Colonna-Dashwood, Reuben Hudd-Baillie, and Charles Spence. 2015. "Latté Art Influences Both the Expected and Rated Value of MilkBased Coffee Drinks." Journal of Sensory Studies 30(4):305-15.

Ehrenreich, Barbara. 2011. Nickel and Dimed: On (Not) Getting By in America. First edition. New York: Picador.

Erickson, Karla. 2004. "To Invest or Detach? Coping Strategies and Workplace Culture in Service Work." Symbolic Interaction 27(4):549-72.

Federal Reserve Bank of New York. 2020. "The Labor Market for Recent College Graduates." Federal Reserve Bank of New York. Retrieved March 20, 2020 (https://www.newyorkfed.org/research/college-labor-market/college-labormarket_underemployment_jobtypes.html).

Fine, Gary Alan. 1992. "The Culture of Production: Aesthetic Choices and Constraints in Culinary Work.” American Journal of Sociology 97(5):1268-94.

Fogg, Neeta P., and Paul E. Harrington. 2011. "Rising Mal-Employment and the Great Recession: The Growing Disconnection between Recent College Graduates and the College Labor Market." Continuing Higher Education Review 75:51-65.

Frenette, Alexandre. 2013. "Making the Intern Economy: Role and Career Challenges of the Music Industry Intern." Work and Occupations 40(4):364-397.

Gabriel, Allison S., Michael A. Daniels, James M. Diefendorff, and Gary J. Greguras. 2015. "Emotional Labor Actors: A Latent Profile Analysis of Emotional Labor Strategies - ProQuest.” Journal of Applied Psychology 100(3):863-79.

Gershon, Ilana. 2017. Down and Out in the New Economy: How People Find (or Don't Find) Work Today. 1 edition. Chicago ; London: University of Chicago Press.

Goffman, Erving. 1973. The Presentation of Self in Everyday Life. Woodstock, N.Y.: Overlook Press.

Goyette, Kimberly A. 2008. "College for Some to College for All: Social Background, Occupational Expectations, and Educational Expectations over Time." Social Science Research 37(2):461-84.

Ham, Maarten van, Clara H. Mulder, and Pieter Hooimeijer. 2016. "Local Underemployment and the Discouraged Worker Effect." Urban Studies.

Heying, Charles. 2010. "Brew to Bikes: Portland's Artisan Economy." Urban Studies and Planning Faculty Publications and Presentations. 
Hochschild, Arlie Russell. 2012. The Managed Heart: Commercialization of Human Feeling. Third Edition, Updated with a New Preface edition. Berkeley Los Angeles London: University of California Press.

Hutchens, Will. 2013. Caffeinated PDX: How Portland Became the Best Coffee City in America. Portland, OR: HFC Media.

Jaffee, Daniel. 2014. Brewing Justice: Fair Trade Coffee, Sustainability, and Survival. Updated edition. Berkeley, California: University of California Press.

Kalleberg, Arne L. 2011. Good Jobs, Bad Jobs: The Rise of Polarized and Precarious Employment Systems in the United States, 1970s-2000s. Russell Sage Foundation.

Karen, David. 2002. "Changes in Access to Higher Education in the United States: 19801992." Sociology of Education 75(3):191-210.

Khan, Linda J., and Paula C. Morrow. 1991. "Objective and Subjective Underemployment Relationships to Job Satisfaction." Journal of Business Research 22(3):211-18.

Klein, Naomi. 2000. No Logo: Taking Aim at the Brand Bullies. 1st Picador USA ed. New York: Picador.

Korver-Glenn, Elizabeth. 2018. “Compounding Inequalities: How Racial Stereotypes and Discrimination Accumulate across the Stages of Housing Exchange." American Sociological Review 83(4):627-56.

Lamont, Michèle. 2000. The Dignity of Working Men: Morality and the Boundaries of Race, Class, and Immigration. New York, N.Y. : Cambridge, Mass.: Russell Sage Foundation; Harvard University Press.

Lane, Carrie M. 2011. A Company of One: Insecurity, Independence, and the New World of White-Collar Unemployment. Ithaca, N.Y.: ILR Press.

Langenkamp, Amy, and Dara Shifrer. 2018. "Family Legacy or Family Pioneer? Social Class Differences in the Way Adolescents Construct College-Going." Journal of Adolescent Research 33(1):58-89.

Lehmann, Wolfgang. 2012. "Extra-Credential Experiences and Social Closure: WorkingClass Students at University.” British Educational Research Journal 38(2):20318.

Leonard, Pauline, Susan Halford, and Katie Bruce. 2016. "'The New Degree?' Constructing Internships in the Third Sector.” Sociology 50(2):383-99. 
Livingstone, D. W. 1998. The Education-Jobs Gap: Underemployment or Economic Democracy. Boulder, Colo.: Westview Press.

Manzo, John. 2010. "Coffee, Connoisseurship, and an Ethnomethodologically-Informed Sociology of Taste." Human Studies; Dordrecht 33(2-3):141-55.

Manzo, John. 2015. “'Third-Wave' Coffeehouses as Venues for Sociality: On Encounters between Employees and Customers." The Qualitative Report 20(6):746-61.

Marvasti, Amir. 2003. Qualitative Research in Sociology. First edition. London ; Thousand Oaks, Calif: SAGE Publications Ltd.

McGuinness, Seamus, Konstantinos Pouliakas, and Paul Redmond. 2018. "Skills Mismatch: Concepts, Measurement and Policy Approaches." Journal of Economic Surveys 32(4):985-1015.

Misra, Joya, and Kyla Walters. 2016. "All Fun and Cool Clothes? Youth Workers' Consumer Identity in Clothing Retail." Work and Occupations 43(3):294-325.

Ocejo, Richard E. 2010. "What'll It Be? Cocktail Bartenders and the Redefinition of Service in the Creative Economy." City, Culture and Society 1(4):179-84.

Ocejo, Richard E. 2012. "At Your Service: The Meanings and Practices of Contemporary Bartenders." European Journal of Cultural Studies 15(5):642-58.

Ocejo, Richard E. 2017. Masters of Craft: Old Jobs in the New Urban Economy. Princeton, New Jersey: Princeton University Press.

Oldenburg, Ray. 1999. The Great Good Place: Cafes, Coffee Shops, Bookstores, Bars, Hair Salons, and Other Hangouts at the Heart of a Community. 3rd edition. New York : Berkeley, Calif.: Marlowe \& Company.

Ragain, Rebecca. 2010. "Portland's Coffee Culture." Pp. 125-37 in Brew to Bikes: Portland's Artisan Economy, edited by C. Heying. Portland, OR: Ooligan Press.

Reynolds, John, Michael Stewart, Ryan MacDonald, and Lacey Sischo. 2006. "Have Adolescents Become Too Ambitious? High School Seniors' Educational and Occupational Plans, 1976 to 2000." Social Problems 53(2):186-206.

Rivera, Lauren A. 2016. Pedigree: How Elite Students Get Elite Jobs. Reprint edition. Princeton University Press.

Rose, Mike. 2005. The Mind at Work: Valuing the Intelligence of the American Worker. Penguin. 
Rosenbaum, James E., and Shazia R. Miller. 1996. "Gatekeeping in an Era of More Open Gates: High School Counselors' Views of Their Influence on Students' College Plans." American Journal of Education 104(4):257-79.

Schneider, Barbara, and David Stevenson. 1999. The Ambitious Generation. Vol. 57. New Haven, CT: Yale University Press.

Schwalbe, Michael. 2010. "In Search of Craft." Social Psychology Quarterly 73(2):10711.

Scurry, Tracy, and John Blenkinsopp. 2011. "Under-employment among Recent Graduates: A Review of the Literature." Personnel Review.

Sedacca, Matthew. 2019. "Why Baristas All Over the Country Are Telling Each Other Their Salaries." Eater. Retrieved January 14, 2020 (https://www.eater.com/young-guns-rising-stars/2019/10/29/20929547/baristaspay-transparency-crowdsourcing-movement).

Sennett, Richard. 2009. The Craftsman. 1 edition. New Haven: Yale University Press.

Standing, Guy. 2016. The Precariat: The New Dangerous Class. Reprint edition. London; New York: Bloomsbury Academic.

Stephens, Nicole M., Tiffany N. Brannon, Hazel Rose Markus, and Jessica E. Nelson. 2015. "Feeling at Home in College: Fortifying School-Relevant Selves to Reduce Social Class Disparities in Higher Education." Social Issues and Policy Review 9(1):1-24.

Timmermans, Stefan, and Iddo Tavory. 2012. "Theory Construction in Qualitative Research: From Grounded Theory to Abductive Analysis." Sociological Theory 30(3):167-186.

Tüzemen, Didem, and Jonathan Willis. 2013. "The Vanishing Middle: Job Polarization and Workers' Response to the Decline in Middle-Skill Jobs." 28.

Van Hook, Jennifer, and Frank D. Bean. 2009. "Explaining Mexican-Immigrant Welfare Behaviors: The Importance of Employment-Related Cultural Repertoires." American Sociological Review 74(3):423-44.

Vedder, Richard, Christopher Denhart, and Jonathan Robe. 2013. Why Are Recent College Graduates Underemployed? University Enrollments and Labor-Market Realities. Center for College Affordability and Productivity.

Yee, April. 2012. "Degree by Default." Contexts 11(4):46-50. 
Yee, April. 2016. "The Unwritten Rules Of Engagement: Social Class Differences in Undergraduates' Academic Strategies." The Journal of Higher Education 87(6):831-58. 
Appendices

Appendix A: Demographic Sheet

1. What is your gender identity?

2. What is your race?

3. Are you from the Portland area?

a. If not, where are you from?

b. How long have you lived in Portland?

4. What is your current living arrangement?

5. Why did you move to/remain in Portland?

6. Where, and in which year, did you receive your bachelor's degree?

7. What is the highest level of education you completed?

a. What was your major and year of graduation?

8. What is the highest education level of your parents/guardians?

9. How many hours per week do you currently work?

10. Do you have any other jobs besides your job as a barista?

11. Do you have any other sources of income or financial help (e.g. family, partner)?

12. Is your place of work part of a chain/franchise system, and if so is it national or local/regional organization? 
Appendix B: Interview Guide

1. [Depending on where they are from] What brought you to/what has kept you in Portland?

2. What made you first want to become a barista?

a. Did you consider/apply for any other types of jobs during that job search? [probe on why they chose barista if relevant]

3. Please share with me the things that you enjoy most about your current job.

a. Prompt on how company is to work for, and how they like working as barista in general.

4. What do you like least about your current job?

a. Prompt on how this compares to previous jobs, especially other barista jobs.

PROMPT: talk about tipping if it hasn't been mentioned in previous two.

5. Please tell me about the customers at your job

a. Interactions

b. Demographics

6. Have you considered leaving?

7. If you left this job, what kind of job would you look for next?

8. Please tell me about the college and major you chose to attend, and why you chose them.

9. At the time that you were finishing school, what were you planning to do after graduation?

10. What's is the job you would most like to have and can imagine yourself getting?

a. Prompt to find out what is holding them back.

11. Is there anything else you'd like to tell me about your job(s), career, and education? 